\title{
Reflections on crafting an ayahuasca community guide for the awareness of sexual abuse
}

\author{
DANIELA PELUSO ${ }^{1 *}$, EMILY SINCLAIR ${ }^{2,3}$, BEATRIZ LABATE $^{3,4}$ and CLANCY CAVNAR ${ }^{3}$ \\ ${ }^{1}$ School of Anthropology and Conservation, University of Kent, Canterbury, UK \\ ${ }^{2}$ Department of Anthropology, Durham University, Durham, UK \\ ${ }^{3}$ Chacruna Institute for Psychedelic Plant Medicines, San Francisco, CA, USA \\ ${ }^{4}$ East-West Psychology Program, California Institute of Integral Studies, San Francisco, CA, USA
}

(Received: November 28, 2019; accepted: January 7, 2020)

\begin{abstract}
This article reflects upon the conception and development of a set of guidelines for the awareness of sexual abuse in ayahuasca settings, an assortment of scenarios that take place in local and global settings entailing the use of a psychedelic brew known for producing visionary and purgative effects composed of Amazonian Banisteriopsis caapi (ayahuasca vine) commonly combined with the leaves of Psychotria viridis (chacruna) or Diplopterys cabrerana (chaliponga). The globalization and diaspora of ayahuasca expertise, usage, and plant materials has broadened the diversity of individual and group interactions and geographical and social contexts in which this hallucinogenic concoction is ingested, and thus given rise to a range of possibilities, which also may, despondently, include possibilities for sexual harassment and abuse. The authors raise the key issues and processes that have led to formation, publication, and dissemination of the Ayahuasca Community Guide for the Awareness of Sexual Abuse of Chacruna Institute for Psychedelic Plant Medicines, focusing specifically on the needs for such guidelines, as well as the challenges faced in collaboratively creating them. The creation of guidelines as an educational task is wrought with concerns, as they must first and foremost convey the fact that abuse is never the victim/survivor's fault, and yet they must also aim to inform individuals of potential common scenarios that can lead to abuse. In this sense, guidelines themselves are held up to scrutiny, and the process of collaboratively crafting the Chacruna Institute's Guide for the Awareness of Sexual Abuse has not been an exception.
\end{abstract}

Keywords: ayahuasca, sexual abuse, consent, code of conduct, ethics, Amazonia

The creation of the Chacruna Institute for Psychedelic Plant Medicines' Ayahuasca Community Guide for the Awareness of Sexual Abuse (herein referred to as "the Guidelines;" see Appendix. The Chacruna Institute Ayahuasca Community Guide for the Awareness of Sexual Abuse) emerged from a process that began with the aim to educate individuals within the psychedelic community about potential common scenarios that can lead to abuse in several contexts pertaining to the consumption of ayahuasca. The formulation of any set of pointers that can be perceived as creating a code of conduct is typically held up to scrutiny; the process of collaboratively crafting a set of guidelines for the awareness of sexual abuse in ayahuasca contexts has been no exception.

The globalization, internationalization, and diaspora of ayahuasca uses and practices have become multifold, multidirectional, and are continually and increasingly on the rise (Fotiou, 2010; Holman, 2010; Labate \& Cavnar, 2014, 2018; Labate, Cavnar, \& Freedman, 2014; Labate, Cavnar, \& Gearin, 2017; Labate \& Jungaberle, 2011). It is now indisputable that ayahuasca has moved from the Amazonian forests to the global stage. In what was once a localized practice, ayahuasca basks in a growing tourism market, and can itself be considered to be in an ongoing process of commodification (Chacruna Institute, 2019; Holman 2010;
Peluso, 2006, 2016; Tupper 2008, 2009, 2016) that has sparked new enterprises and expertise to the extent that it can be referred to as an "entrepreneurial industry" (Peluso, 2016, p. 203). Whether it is discussed on The Late Show with Stephen Colbert, included in mainstream cinema, consumed at the sporadic rave, debated at global academic conferences, featured in the writings of psychonauts, or appeared as a key interest of the broader psychedelic community, ayahuasca has undoubtedly been holding its place in the spotlight. Part of this enormous growth and popularity has led to increased contexts of the abuse of power, intercultural communication and miscommunication, the proliferation of inexperienced shamans, and vast power differentials that have fueled the unacceptable reality that ayahuasca ceremonies can become potential spaces where sexual abuse can occur (Fernández, 2018; Peluso, 2014a, 2018; Sinclair \& Labate, 2019). While the number of women partaking and assuming ceremonial leadership within the context of ayahuasca tourism is increasing, the problem of sexual abuse of women has also been

\footnotetext{
* Corresponding author: Daniela Peluso; School of Anthropology and Conservation, University of Kent, Marlowe Building, Canterbury, Kent CT27NR, UK; Phone: +44 1227824 885; E-mail: D.Peluso@kent.ac.uk
}

This is an open-access article distributed under the terms of the Creative Commons Attribution-NonCommercial 4.0 International License, which permits unrestricted use, distribution, and reproduction in any medium for non-commercial purposes, provided the original author and source are credited, a link to the CC License is provided, and changes - if any - are indicated. 
increasing [In examining Amazonian ayahuasca practices outside of the context of ayahuasca tourism, we find that, in many communities, women have had, and continue to have, access to shamanic knowledge and, indeed, have been formally or informally "shamanizing" (Perruchon, 2003). Notwithstanding, female leadership roles within ayahuasca communities commonly grapple with challenges that reflect local gender relationships and norms (Herbert, 2010; Virtanen, 2016).]. This is an overall unacceptable development, as all occurrences of sexual abuse are unacceptable, and should not be tolerated. The harm of instances of sexual abuse is compounded, since many ayahuasca participants are in search of healing from their own former traumas, often also brought forth from sexual abuse, and are not aware that sexual abuse can also happen in a setting meant for healing (Peluso, 2014a; Sinclair \& Labate, 2019; Trichter, 2010). Indeed, one of the first obstacles researchers and organizations face in addressing issues surrounding sexual abuse within the ayahuasca community is the widespread disbelief that the problem exists. Labate (2012) gave a presentation, titled "Reflections on Problematic Occurrences Involving Sex and Seduction in the Ayahuasca Field," at the Women's Visionary Congress in Petaluma, addressing her own experiences working with a shaman who she later found out led a double life. The presentation referenced Daniela Peluso's forthcoming research (in press for Labate \& Cavnar's 2014 volume, completed in 2011). Peluso's (2014a, 2014b) publications focused exclusively on shaman's participant seduction in ayahuasca settings. Later, in the same year, Cavnar (2014) and Peluso (2014b) presented on the issues of gender, power, and sexuality in the I World Ayahuasca Conference in Ibiza, and in December 2014, the Women Visionary Congress (WVC, 2014) published their tips on safety in ceremonies. Since then, there has been an increasing number of scholarly publications noting the problem of sexual misconduct in ayahuasca communities (Fernández, 2018; Méndez, 2015; Molnar, 2019; Peluso, 2018; Sanchez Sarmiento, 2018, 2019). In addition, several high-profile cases have also come to light in recent years across diverse ayahuasca ceremonial contexts that have shown that such occurrences are more widespread than previously thought. Nonetheless, many participants seeking ayahuasca healing remain unaware of this potential risk and can unwittingly find themselves in a vulnerable situation.

As part of the Chacruna Institute for Psychedelic Plant Medicines' (herein referred to as "Chacruna") overall mission to educate the public on plant substances and their cultural aspects and legitimacy, alongside the organization's motivation to raise awareness of sexual abuse and help to safeguard individuals and groups in ayahuasca healing contexts, the Ayahuasca Community Guide for the Awareness of Sexual Abuse was created. The Guidelines consist of an introduction outlining the problem and include a set of pointers regarding the most common scenarios in which abuse has occurred and continues to transpire. Here, Chacruna aims to educate individuals about what might be expected from typical ceremonial practices, so that ayahuasca consumers can be aware of any diversions that could potentially foster sexual transgressions. In this way, the Guidelines aim to inform individuals in advance of their potential experiences in ayahuasca's Amazonian cultural contexts, providing the necessary information to make autonomous choices that best suit them. This aim rests upon the notion that, with knowledge and awareness of past and potential sexual abuse contexts, individuals and groups can better begin to combat such occurrences in the present and future.

The decision to focus the Guidelines on women is because the majority of sexual abuse cases involves female participants and male shamans. Nonetheless, the Guidelines address issues across genders and are of value to all. In addition, the Guidelines aim to create positive dialogue and action across the ayahuasca community, hoping to include all individuals in terms of both raising awareness and working toward solutions. Attempting to cover diverse social and cultural settings where ayahuasca healing takes place, the Guidelines have been created through a collaborative process with experienced individuals in a wide range of ayahuasca settings across different cultural contexts and continents. This shared process - which compiled data from various intensive feedback stages - has included indigenous as well as Western victims and survivors of abuse, ayahuasca healers and ceremonial facilitators, and social scientists who, like ourselves, have conducted long-term fieldwork in lowland South America and have longstanding experience with diverse ayahuasca communities.

The Guidelines also aim to be relevant across the wide spectrum of potential abuse that can occur in ayahuasca settings, including verbal persuasion, invasive touching, "consensual" sex between healer and participant, and rape. In striving to reach the worldwide ayahuasca community, Chacruna has made the Guidelines available in multiple languages viewable online and in downloadable formats free of charge. In a complementary effort, Chacruna has also launched the Legal Resources Companion to the Guidelines for the Awareness of Sexual Abuse (https://chacruna.net/legalresources-companion-to-the-guidelines-for-the-awarenessof-sexual-abuse/), which offers ready-at-hand information on a country-by-country basis regarding government laws about sexual abuse, overviews of centers, and resources that are available. Yet, Chacruna's hope is that the Guidelines for the Awareness of Sexual Abuse will make the Legal Companion less necessary.

In addition to acknowledging that sexual abuse is an abuse of power that occurs broadly across diverse contexts in distinct societies, Chacruna is interested in ascertaining if there are common threads that are repeatedly associated with sexual misconduct in ayahuasca-healing contexts. As already noted, sexual abuse of women in the ayahuasca community occurs across and within cultures. Yet, research and experience indicate that the potential for abuse is further exacerbated by cultural differences in the current context of the increasing globalization of ayahuasca, whereby many Western people now partake in ayahuasca ceremonies in South American contexts, or whereby South American healers travel to the Global North (Peluso, 2014a). Mutual crosscultural misunderstandings and misconceptions between healers and participants can certainly create confusion at least, and can be brutally manipulated at worst. The main aim of the Guidelines is to equip individuals with information in these culturally unfamiliar contexts where ayahuasca ceremonies often take place as a form of empowerment. 
A common consistently reoccurring theme is the undue romanticism that can typically surround expectations about ayahuasca and ayahuasqueros, and the subsequent position of trust a healer or ceremonial facilitator inhabits in the imagination of participants. Many ayahuasca participants, new and veteran, hold impractical views of shamans and ceremonial leaders, imagining them to be God-like saints or spiritual gurus. However, within their native communities, ayahuasqueros are viewed as normal men with varying degrees of healing talents who do not necessarily occupy esteemed community positions or live according to Western moral conventions (Peluso, 2014a). One of the key aims of the Guidelines, therefore, is to demystify the position of the ayahuasca healer.

Many ayahuasqueros, both local and non-local, can take advantage of romanticized notions that individuals have on them as healers and use their idealized position to manipulate others for their own personal sexual gratification. Such unrealistic viewpoints, combined with an overall unfamiliarity of what to expect in healing sessions, can further increase one's defenselessness. A common context for this is, during individual healings, known as sopladas or limpiezas, where participants might be naive about what constitutes usual levels of touching and nudity, and their unfamiliarity about such matters might make it difficult for them to decide on the spot where to "draw a line," thus increasing their vulnerability to abuse. Many reported cases suggest that it is common for women to be invited by ayahuasca healers for "special" healing experiences, and then be manipulated or forced into sexual acts. For this reason, the Chacruna Guidelines explain that nudity is not typical and that shamans do not customarily require their patients to remove undergarments for the purposes of healing.

While the Guidelines may appear to be overly directive, risking the allegation of telling individuals what they can and cannot do with their own bodies, it would be disingenuous not to advise individuals who will be placing themselves in an unfamiliar setting, an already inherently vulnerable context, of what the typical basic ground rules are, and what some of the high-risk probable occurrences might be. With knowledge of the Guidelines in advance of ayahuasca events, individuals can be aware of common manipulative techniques that sexual abuse perpetrators typically employ.

The greater awareness of the occurrence of sexual abuse has also led to a rise in demand for female healers, many of whom now hold prominent positions in established centers around the world. Furthermore, all female staffed retreats have also been established in recent years. Although the Guidelines encourage women to drink in groups with female facilitators or experienced women present, they do not intend to alienate men. It is noteworthy that there are several male healers and ceremonial facilitators and participants working with ayahuasca with great integrity and who are also outraged by sexual abuse in ayahuasca settings. Similarly, it is important to emphasize that not all female healers or facilitators are trustworthy. Communication across genders and cultural differences is necessary for constructive dialogue around sexual misconduct and its elimination.
Mutual consent is a complex and critical issue that the Guidelines strive to raise as a significant point of consideration. Research, interviews, and personally related accounts suggest that some incidents of abuse occur in contexts that can be spoken in precarious "consensual" terms. Consent, how it is understood and negotiated, is the basis for all respectful interactions. For consent to be effective, individuals minimally need to engage in communication that is mutually intelligible, so that meanings are shared and intentions are clarified, with an understanding that consent always occurs within specific socio-cultural-political contexts (Alexiades \& Peluso, 2002). Indeed, consent and the policies surrounding consent are only as effective as peoples' understanding and use of them (Borges, Banyard, \& Moynihan, 2008). For these reasons, it can happen that, at the time of an affirmative "consent," all things might appear to be equal; yet, such equality is often difficult to ascertain. Furthermore, as in healer-patient dynamics, the healer is in a position of power and responsibility that creates an imbalance, by default, between the parties. While some healers may just take this for granted as a given inequality, there are some healers who abuse these uneven power relations to manipulate women into having sex with them.

Similar patterns of abuse of power are commonplace and widespread throughout religious, therapeutic, and spiritual settings (Rutter, 1995), and the bulk of these cases, similar to what is concurrent with incidents across youth today, is a result of verbal pressuring and persuasion that places individuals in regretful situations (Powell, 2010; Pugh \& Becker, 2018). Indeed, in some shamanic ayahuasca practices, there are techniques specifically employed to induce feelings of sexual attraction; these techniques are collapsed together with local cultural concepts of "hunting" as a compatible form of seduction (Luna, 2011; Peluso, 2014a). For instance, many women have reported that they were manipulated into sexual acts through the use of a variety "charm spells." Yet, aphrodisiacs, sexual stimulants, and other techniques or knowledge systems are part of the Amazonian pharmacopeia and are generically known among local populations (Elisabetsky \& Shanley, 1994); thus, they are not necessarily exclusively shamanic. While such claims address intangible aspects of shamanic practices, they remain a unique feature that is linked to numerous instances of reported sexual abuse regarding ayahuasca and shamanic healing circles. In such cases, where ayahuasca participants are actively seduced or targeted by a healer or facilitator, they are often unaware that they are being manipulated or influenced by the power dynamics of the context in which they are situated, thus making the grounds for mutual consent shaky. Indeed, researchers have been challenged to recognize and align social perceptions toward the "criminal regulation of sexual misconduct with the ever-evolving social perceptions about sexuality and gender norms" (Buchhandler-Raphael, 2011, p. 149). This has meant that, in the past, legal systems considered rape to be a coercive non-consented act, whereas, currently, rape reform laws in many states and countries now take into account how power is used to intimidate and take advantage of others in ways that diminish their ability to consent. Thus, sexual acts that had formally been seen as sexual harassment and discrimination on the basis of one's ability to consent 
now warrant criminal penalties (Schulhofer, 1998). This emphasizes how critical it is for individuals to obtain freely given, unambiguous, affirmative consent from each other, so that individual bodily and sexual autonomy is respected and adhered to. Any deviation from unhindered positive consent is a form of sexual abuse.

Another common scenario in reported abuse attempts or occurrences is that some healers might suggest to a participant that having sex with them is a form of healing, or a way to gain spiritual power. They can also attempt to substantiate this by purporting that these extramarital relations are morally acceptable to their wives or partners. In cases where women might agree to relations with shamans, they might be given a special position in an ayahuasca ceremonial space in an attempt to make them feel special or gifted, thus encouraging them to continue to engage in sexual relations. When sexual abuse happens along these lines, following such incidents, women are often confused and ashamed and feel unable to speak up, often believing that they are limited in their ability to accuse the shamans, religious leaders, and other perpetrators of abuse with whom the accountability actually lies. The Guidelines are aimed at empowering participants by exposing them to the knowledge and possibility of such deceptive scenarios, so that they can make informed decisions and also speak out in cases where they might be doubtful if interactions were appropriate.

Research and personal accounts also show that many women stand by their decisions of mutual consensual sex with shamans or their assistants and have no regrets (Peluso, 2014a). Some individuals, for a variety of reasons, are attracted to the possibility of having sex with a shaman or ceremonial leader, and may actively pursue sexual relations with them. While the Guidelines do not denounce such encounters, they highlight the importance for individuals to integrate their ayahuasca experiences and encourage them to allow time for the effects of ayahuasca to wear off in order for them to "come back down to earth" and feel grounded, so they can apply their own individual clear judgment. As stated in the Guidelines, sexual relations between healers and participants during or shortly following ceremonies are considered inappropriate in all ayahuasca traditions. It is the healer or facilitator's responsibility to resist entering into relationships with ceremonial participants within the healing space, even if women might approach them with this intention. This is an aspect that shamans frequently have a hard time understanding, and in the future, we would like to find ways to better create and foster these intercultural conversations.

The Guidelines do not deny that loving and sexual relationships can potentially be established between ceremonial facilitators and participants in ayahuasca circles. However, as with doctors or therapists and patients, it is widely agreed that this is a transgression in healing contexts, particularly when it occurs between two people not known to each other prior to taking ayahuasca together. However, unlike the health profession, there is not a code of ethics nor commonplace rules or guidance as to how long afterward parties should wait outside the healing context, if they are considering initiating a relationship. Indeed, this topic generates contentious disagreements within the ayahuasca community. Chacruna's purpose with the Guidelines is to create a healthy conversation around these delicate issues, and to raise awareness about the complexities of "consensual" sex, so that individuals can be informed and thus empowered by such knowledge, enabling them to make their own choices.

Additionally, and of increased importance, is the question of whether consent, either willfully given or affirmatively embarked upon, can be properly granted under any circumstances in any ayahuasca setting. This question is open to much debate and raises broader contemplation about the validity of consent and the use of psychedelics at large. The combination of sex and psychedelics has a long history of acceptance (Dawson, 2019; Gay, Newmeyer, Elion, \& Wieder, 1977; Hoffman, Dass, \& Shulgin, 2014; Sprinkle, 2003) and raises a multitude of diverse social and individual circumstances that complicate the understanding of mutually intelligible affirmative consent. While renowned psychonauts such as Timothy Leary hailed such a combination, as did ayahuasca pioneer McKenna (1999) - who referred to the bringing together of sex and psychedelics as "the Mount Everest of the experience" - the variable legal status of psychedelics means that consent is never legally grantable in any context in which an individual is affected by a classified drug. In this sense, it is important to note that the classification and status of ayahuasca as an illegal drug varies across location (Labate \& Jungaberle, 2011; see Tupper, 2012), which adds to the complexity of legal issues of consent.

Nonetheless, broader questions of whether consent can ever be granted in any circumstances in which one or more individuals are in an altered state of consciousness, regardless of a substance's legality, need to be considered. The legal system has ruled variably on degrees of capacity and consent (see, for instance, Cowan, 2008 for a discussion of degrees of intoxication and consent). Legal competence and consent require individuals to have full mental capacity. In addition, court cases have ruled that it is not legally binding for individuals to consent in advance to sexual activity whereby they will be unconscious (Koshan, 2011), implicating that consent in altered states of consciousness cannot be premeditated, particularly as consent is an ongoing process. Furthermore, legal consent requires that an individual have the "freedom and capacity" to consent in a context that is free from "gifts, alcohol, and drugs" (Crown Prosecution Service, 2003, p. 1; see also Rape, Abuse \& Incest National Network, 2019). Conventionally, following these parameters, sex and psychedelics are legally meant to remain separate. Clearly, the issue of consent regarding sex with the use of psychedelics needs a greater nuance of understanding and increased and ongoing discussions across ayahuasca and psychedelic circles.

Processes for developing the Guidelines have been intricate, fruitful, and worthwhile; yet, Chacruna recognizes that their dissemination must be accessible to as many individuals and groups as possible for them to have an impact on informing individuals about sexual abuse. At present, the Guidelines are now available without charge on Chacruna's website (chacruna.net). They have been read by over 12,000 people since November 2019 (Chacruna Guidelines website data, Google Analytics), and they are downloadable in nine languages (English, Spanish, Portuguese, Italian, French, German, Dutch, Russian, and Ukrainian), with further 
translations forthcoming. Chacruna's social media team actively distributes these throughout and across the ayahuasca community, alongside multiple presentations on this subject at psychedelic and academic conferences and through podcasts. In addition, Chacruna has delivered the Guidelines directly to retreat centers and local communities in the Iquitos region of Peru (Sinclair, 2019), an area that is considered to be the Mecca of ayahuasca tourism (Labate \& Cavnar, 2014; Losonczy \& Mesturini, 2010, 2011; Suárez, 2014). This also served as an opportunity for further indepth research on how the Guidelines resonate with local centers and communities, how they are interpreted, and what their value is locally. This has thus far been a positive "next step" in spreading awareness of sexual abuse in ayahuasca contexts.

As mentioned earlier, in addition to the Guidelines, and as a complement to the efforts of the Guidelines, Chacruna has also researched and developed a Legal Resources Companion to the Guidelines for the Awareness of Sexual Abuse. The Legal Resources Companion, also available online free of charge, provides information about policies and laws in relation to sexual abuse on a country-by-country basis. It provides contacts and locations where one can promptly seek information and support from trustworthy organizations should an incident of abuse occur. The Legal Resources Companion will also be available in several languages. It is currently available for Peru, Brazil, Costa Rica, and Bolivia with Spanish translations and will expand to include several additional South American countries and additional translations. Similar to the Guidelines, The Legal Resources Companion was created through collaboration with people across the ayahuasca community, including legal and sexual abuse experts and knowledgeable practitioners and participants in the countries they focus on. These collaborative efforts have been crucial to this initiative and Chacruna views them as continuing to be pivotal in moving forward with spreading awareness about sexual abuse across ayahuasca communities.

Importantly, the Guidelines encourage people to not be bystanders. They are also already exerting influence in local settings whereby shamans, facilitators, and everyday citizens are reading about sexual abuse in their own language and thus making strides to comprehend tourist experiences while also being encouraged to also speak out against abuse. This seems especially important in countries where patriarchy and stereotypical gender roles often naturalize women's behavior as being submissive to men. Such important incremental long-term changes are cumulative and will hopefully eliminate the need for the Legal Resource Companion as sexual abuse becomes viewed as more of a community responsibility rather than just an individual one. Until that day, the Guidelines will provide insights of potential contexts for sexual abuse, and in doing so will equip newcomers and veterans alike, to be as informed as possible.

Sexual abuse affects people beyond ayahuasca-healing contexts. In fact, the abuse that transpires in ayahuasca circles is part of a global epidemic of violence against women and vulnerable others. Estimated worldwide figures state that $35 \%$ of women have experienced physical or sexual violence; national estimates are in some cases as high as 70\% (UN Women, 2015). Therefore, it is vital to find ways to transform social norms to protect everyone against all forms of violence. The Guidelines, with their own humble yet focused approach, in communicating locally and internationally across borders, cultures, and languages, aim to provide individuals with knowledge while also building allies to unite against the abhorrent problem of sexual violence. The psychedelic community is concerned with the expansion of consciousness, not just one's individual consciousness, but also the consciousness of the community and the greater world. With such extraordinary goals, there is no place for abuse in any of its forms or guises.

Acknowledgements: For assistance with the Guideline translations, the authors are grateful to Liliane Alexiades, Marianne Bies, Raffaela Deplazes, Sonia Labate, Alexandra Leduc-Pagel, Alla Perminova, and Pierra Talin, with additional support from Miguel Alexiades, David Dupuis, Denys Krupodorov, Ariadne Los, Francesca Mezzenzana, and Ronald Weber. They would also like to thank Aphroditi Pina for her expert advice and the anonymized support of countless individuals with whom they collaborated for providing ongoing conversation and critical feedback.

Conflict of interest: The authors declared no conflicts of interest.

\section{REFERENCES}

Alexiades, M., \& Peluso, D. M. (2002). Prior informed consent: The politics of cross-cultural exchange. In S. A. Laird (Ed.), Biodiversity and traditional knowledge: Equitable partnerships in practice. London: Earthscan.

Borges, A. M., Banyard, V. L., \& Moynihan, M. M. (2008). Clarifying consent: Primary prevention of sexual assault on a college campus. Journal of Prevention \& Intervention in the Community, 36(1-2), 75-88. doi:10.1080/108523508020 22324

Buchhandler-Raphael, M. (2011). The failure of consent: Reconceptualizing rape as sexual abuse of power. Michigan Journal of Gender \& Law, 18(1), 147-228. Retrieved from https://repository.law.umich.edu/mjgl/vol18/iss1/4

Cavnar, C. (2014, September). Reflections on spirituality, gender and power in my experience with Santo Daime. Paper presented at the I World Ayahuasca Conference, Palau de Congressos, Ibiza, Spain. Retrieved from http://neip.info/novo/wp-content/ uploads/2015/04/clancy-cavnar-gender-session-world-ayahuascaconference-2014.pdf

Chacruna Institute for Psychedelic Medicines. (2019, October 11). The commodification of ayahuasca: How can we do better? Chacruna.net. Retrieved from https://chacruna.net/ the-commodification-of-ayahuasca-how-can-we-do-better/

Cowan, S. (2008). The trouble with drink: Intoxication, (in) capacity, and the evaporation of consent to sex. Akron Law Review, 41(4), 899-922.

Crown Prosecution Service (CPS). (2003). What is consent. Retrieved from https://www.cps.gov.uk/sites/default/files/ documents/publications/what_is_consent_v2.pdf 
Dawson, A. (2019, May 22). Psychedelics, sex, and consent: A brief history. Chacruna.net. Retrieved from https://chacruna. net/psychedelics-sex-and-consent-a-brief-history/

Elisabetsky, E., \& Shanley, P. (1994). Ethnopharmacology in the Brazilian Amazon. Pharmacology \& Therapeutics, 64(2), 201-214. doi:10.1016/0163-7258(94)90039-6

Fernández, A. C. (2018). Power and legitimacy in the reconfiguration of the yagecero field in Colombia. In B. C. Labate \& C. Cavnar (Eds.), The expanding world ayahuasca diaspora (pp. 199-216). New York, NY: Routledge.

Fotiou, E. (2010). From medicine men to day trippers: Shamanic tourism in Iquitos, Peru (Doctoral dissertation). University of Wisconsin-Madison, Madison, WI.

Gay, G. R., Newmeyer, J. A., Elion, R. A., \& Wieder, S. (1977). The sensuous hippie: I. Drug/sex practice in the HaightAshbury. Drug Forum, 6(1), 27-47.

Herbert, A. (2010). Female ayahuasca healers among the ShipiboKonibo (UcayaliPeru) in the context of spiritual tourism. Núcleo de Estudos Interdisciplinares sobre Psicoativos (NEIP). Retrieved from http://neip.info/novo/wp-content/ uploads/2015/04/herbert_female_ayahuasca_healers_shipibo_ spiritual_tourism.pdf

Hoffman, A., Dass, R., \& Shulgin, S. (2014). Manifesting minds: A review of psychedelics in science, medicine, sex, and spirituality. Berkeley, CA: North Atlantic Books.

Holman, C. L. (2010). Spirituality for sale: An analysis of ayahuasca tourism (Doctoral dissertation). Arizona State University, Tempe, AZ.

Koshan, J. (2011). Consciousness and consent in sexual assault cases [Blog post]. ABlawg: The University of Calgary Faculty of Law Blog. Retrieved from https://ablawg.ca/wp-content/ uploads/2011/06/blog_jk_ja_june2011.pdf

Labate, B. C. (2012). Reflections on problematic recurrences involving sex and seduction in the ayahuasca field. Paper presented at the Women's Visionary Congress: Consciousness, Healing and Social Justice Institute of Noetic Sciences (IONS). Petaluma, CA.

Labate, B. C., \& Cavnar, C. (Eds.). (2014). Ayahuasca shamanism in the Amazon and beyond. New York, NY: Oxford University Press.

Labate, B. C., \& Cavnar, C. (Eds.). (2018). The expanding world ayahuasca diaspora: Appropriation, integration and legislation. New York, NY: Routledge.

Labate, B. C., Cavnar, C., \& Freedman, F. B. (2014). Notes on the expansion and reinvention of ayahuasca shamanism. In B. C. Labate \& C. Cavnar (Eds.), Ayahuasca shamanism in the Amazon and beyond (pp. 3-15). Oxford, UK: Oxford University Press.

Labate, B. C., Cavnar, C., \& Gearin, A. K. (Eds.). (2017). The world ayahuasca diaspora: Reinventions and controversies. New York City, NY: Routledge.

Labate, B. C., \& Jungaberle, H. (Eds.). (2011). The internationalization of ayahuasca. Zurich, Switzerland: Lit Verlag.

Losonczy, A. M., \& Mesturini, S. (2010). La selva viajera: rutas del chamanismo ayahuasquero entre Europa y América [The jungle travels: Ayahuasquero shamanism paths between Europe and America]. Religião \& Sociedade, 30(2), 164-183. doi:10.1590/S0100-85872010000200009

Losonczy, A. M., \& Mesturini, S. (2011). Por que ayahuasca? $\mathrm{Da}$ internacionalização de uma prática ritual ameríndia [Why ayahuasca? The internationalization of an Amerindian ritual practice]. Anuário Antropológico, I, 9-30. doi:10.4000/ aa.986

Luna, E. (2011). Some reflections on the global expansion of ayahuasca. In B. C. Labate \& H. Jungaberle (Eds.), The internationalization of ayahuasca (pp. 123-129). Zurich, Switzerland: Lit Verlag.

McKenna, T. (1999, September). Posthumous glory. Paper presented at Alchemical arts conference, Honolulu, HI. Retrieved from http:/www.matrixmasters.net/podcasts/TRANSCRIPTS/ TMcK-PosthumousGlory.pdf

Méndez, M. (2015). Ayahuasca: una introducción para profesionales chilenos de la salud mental [Ayahuasca: An introduction for Chilean mental health professionals]. Gaceta de Psiquiatría Universitaria, 11(4), 402-411.

Molnar, E. (2019). The bioethics of psychedelic guides: Issues of safety and abuses of power in ceremonies with psychoactive substances. In M. Papaspyrou, C. Baldini, \& D. Luke (Eds.), Psychedelic mysteries of the feminine: Creativity, ecstasy, healing (pp. 167-181). Rochester, VT: Park Street Press.

Peluso, D. M. (2006). For 'export only': Ayahuasca tourism and hyper-traditionalism. In N. AlSayyad (Ed.), IASTE 2006 Working Paper Series (Hyper-Traditions and "Real" Places) (Vol. 189, pp. 482-500). Berkeley, CA: University of California, Berkeley.

Peluso, D. M. (2014a). Ayahuasca's attractions and distractions: Examining sexual seduction in shaman-participant interactions. In B. C. Labate \& C. Cavnar (Eds.), Ayahuasca shamanism in the Amazon and beyond (pp. 231-255). Oxford, UK: Oxford University Press.

Peluso, D. M. (2014b, September). Shaman-participant sexual seduction in ayahuasca settings. Paper presented at the I World Ayahuasca Conference, Palau de Congressos Ibiza, Spain.

Peluso, D. M. (2016). Global ayahuasca: An entrepreneurial ecosystem. In B. C. Labate, C. Cavnar, \& A. K. Gearin (Eds.), The world ayahuasca diaspora: Reinventions and controversies (pp. 203-221). New York, NY: Routledge.

Peluso, D. M. (2018, October 5). Ayahuasca's attractions and distractions: Examining sexual seduction in shamanparticipant interactions. Chacruna.net. Retrieved from https:// chacruna.net/sexual-seduction-ayahuasca-shaman-participantsinteractions/

Perruchon, M. (2003). I am Tsunki: Gender and shamanism among the Shuar of Western Amazonia. Uppsala, NY: Uppsala University Press.

Powell, A. (2010). Sex, power, and consent: Youth culture and the unwritten rules. Melbourne, Australia: Cambridge University Press.

Pugh, B., \& Becker, P. (2018). Exploring definitions and prevalence of verbal sexual coercion and its relationship to consent to unwanted sex: Implications for affirmative consent standards on college campuses. Behavioral Sciences, 8(8), 69. doi:10.3390/ bs 8080069

Rape, Abuse \& Incest National Network. (2019). Legal role of consent. Retrieved from https://www.rainn.org/articles/legalrole-consent

Rutter, P. (1995). Sex in the forbidden zone: When men in power abuse women's trust. London, UK: Aquarian Press.

Sánchez Sarmiento, B. (2018). Neochamanismo urbano. Engaño, abuso y poder en la comunidad Carare [Urban neoshamanism: 
Deception, abuse and power in the Carare community]. Intervenciones En Estudios Culturales. Bogotá, Colombia: Pontificia Universidad Javeriana.

Sánchez Sarmiento, B. (2019, October 4). How I lived twelve years in a Colombian ayahuasca cult led by a sexual abuser. Chacruna.net. Retrieved from https://chacruna.net/how-i-livedtwelve-years-in-a-colombian-ayahuasca-cult-led-by-a-sexualabuser/

Schulhofer, S. J. (1998). Unwanted sex: The culture of intimidation and the failure of law. Cambridge, MA: Harvard University Press.

Sinclair, E. (2019, November 22). Ayahuasca community outreach: Distribution of the Guidelines for the Awareness of Sexual Abuse in Iquitos, Peru. Chacruna.net. Retrieved from https://chacruna.net/ayahuasca-community-outreachdistribution-of-the-guidelines-for-the-awareness-of-sexualabuse-in-iquitos-peru/

Sinclair, E., \& Labate, B. C. (2019). Ayahuasca community guide for the awareness of sexual abuse. MAPS Bulletin, 29(1). Retrieved from https://maps.org/news/bulletin/articles/ 436-maps-bulletin-spring-2019-vol-29,-no-1/7825-ayahuascacommunity-guide-for-the-awareness-of-abuse-spring-2019

Sprinkle, A. (2003). How psychedelics informed my sex life and sex work. Sexuality \& Culture, 7(2), 59-71. doi:10.1007/s12119003-1012-8

Suárez, C. (2014). Iquitos: meca de la ayahuasca: Benigno es bueno [Iquitos: Ayahuasca Mecca: Benigno is good]. Cañamo: La revista de la cultura del cannabis, 198, 98-107.
Trichter, S. (2010). Ayahuasca beyond the Amazon: The benefits and risks of a spreading tradition. Journal of Transpersonal Psychology, 42(2), 131-148.

Tupper, K. W. (2008). The globalization of ayahuasca: Harm reduction or benefit maximization? International Journal of Drug Policy, 19(4), 297-303. doi:10.1016/j.drugpo.2006.11.001

Tupper, K. W. (2009). Ayahuasca healing beyond the Amazon: The globalization of a traditional indigenous entheogenic practice. Global Networks, 9(1), 117-136. doi:10.1111/j.14710374.2009.00245.x

Tupper, K. W. (2012). Psychoactive substances and the English language: "Drugs," discourses and public policy. Contemporary Drug Problems, 39(3), 461-492. doi:10.1177/00914 5091203900306

Tupper, K. W. (2016). The economics of ayahuasca: Money, markets, and the value of the vine. In B. C. Labate, C. Cavnar, \& A. K. Gearin (Eds.), The world ayahuasca diaspora: Reinventions and controversies (pp. 203-222). London, UK: Routledge.

Virtanen, P. K. (2016). Shamanism and indigenous youthhood in the Brazilian Amazon. Amazônica-Revista de Antropologia, 1(1), 152-177. doi:10.18542/amazonica.v1i1.146

Women Visionary Congress (WVC). (2014). 20 safety tips for those participating in ceremonies that use psychoactive substances. Retrieved from https://www.visionarycongress. org/safety-tips-for-participating-in-psychedelic-ceremonies

UN Women. (2015). Facts and figures: Ending violence against women. Global database on violence against women. Retrieved from https://www.unwomen.org/en/what-we-do/ ending-violence-against-women/facts-and-figures\#notes 


\section{APPENDIX}

The Chacruna Institute Ayahuasca Community Guide for the Awareness of Sexual Abuse

Abuse is never your fault. If anything happens, speak up, reach out!

Sexual abuse and misconduct toward female participants in ayahuasca circles are, unfortunately, quite prevalent. Exact numbers are difficult to obtain, as most cases never come to light; nonetheless, the issue is common knowledge within the ayahuasca community. As an organization dedicated to providing public education and cultural understanding about plant medicines, we are at the Chacruna.

Institute for Psychedelic Plant Medicines does not wish to dissuade women from drinking ayahuasca, but rather to raise awareness about sexual harassment, and offer practical guidelines in the interest of keeping female participants in ayahuasca ceremonies and communities safe. While our guide is aimed toward preventing female participant abuse by male shamans, where the most commonplace abuses have occurred, we also acknowledge that abuse happens by and toward other genders. This guide embraces a culturally sensitive approach toward raising awareness and the avoidance of abuse in typical scenarios without diminishing the fact that abuse is unlawful and unacceptable in all circumstances.

Why does sexual assault occur in ayahuasca-healing contexts?

Sexual assault in ayahuasca settings involves a wide spectrum of abuse, including invasive touching, "consensual" sex between healer and participant, and rape. The abuse of participants by healers and facilitators in ayahuasca ceremonial contexts, such as any sexual assault, is an abuse of power. It is a gross perversion of the healer-participant dynamic, in which the healer or facilitator uses their position of power and responsibility to gratify personal sexual and power interests. This is especially harmful and shocking considering many women who drink ayahuasca are seeking healing for sexual traumas suffered in the past. Sexual relations between healer and patient or religious leader and follower are an obvious violation of healer-patient and religious codes of conduct. The globalization of ayahuasca presents complex crosscultural interactions where local and global moral codes and gender relational norms often come into contact and conflict, further complicating healer-patient and religious leaderfollower relations. Many Western people now partake of ayahuasca ceremonies in South American contexts where mutual misconceptions of the "other" are commonplace. For instance, "shamans" are often highly romanticized in the Western imagination as being perfect beings or God-like. Some South American, and indeed Western, men have learned to take advantage of some of these exalted images of healers. Equally unjustly, local men may view Western women as sexually promiscuous. Economic inequalities and incentives further complicate these cross-cultural interactions whereby local healers may attempt to improve their financial prospects and social standing through entering into relations with Western women. This is especially prevalent in the current context of the commercialization of ayahuasca. Yet, these cross-cultural considerations cannot fully explain sexual abuse in ayahuasca contexts, since South American women are also sexually abused by South American healers and Western women by Western healers.

Sexual abuse between healer and patient is evident in spiritual and healing communities across cultures and throughout time. As in these wider contexts, many shamans or religious leaders claim to possess special powers that can heal others; some might promote "tantric" exercises and sexual contact that they claim can heal someone from past traumatic experiences.

They may argue that this will be a way to "regain the sacred energy of sex," and that "society is moralistic and does not understand the freedom of sex," etc., to gain sexual favors. Instances of so-called "consensual" sex between healer and patient as well as religious leader and follower often involve great power imbalances and intentional deception and manipulation on the part of the healer. The establishment of allegedly consensual relationships poses several challenges.

Chacruna recognizes that there are many healers, religious leaders, and facilitators working with ayahuasca with great integrity. Being aware of potentially relevant contexts in which misconduct has taken place allows us to make informed choices. All individuals have their own bodily autonomy and the right to make their own choices. All individuals have the right to say "no" to any situation they are not comfortable with, and the right to withdraw themselves from any situation that they are not comfortable in. Here, we offer for your consideration guidelines relevant to typical contexts of abuse.

These guidelines were created through collaboration with women and men in the ayahuasca community across different cultural contexts, including indigenous as well as Western victims and survivors of abuse, and ayahuasca healers and ceremonial facilitators. Researchers and regional experts have also been consulted. Please note that this guide is trying to cover indigenous, mestizo, religious, therapeutic, neoshamanic, and New Age circles, so not all items are applicable to all contexts.

Please use your best judgment.

Safety Guidelines

1. Consider drinking with friends. Partaking in ayahuasca in ceremonies or any healing practice alone with the healer has been a common context in which sexual abuse has occurred. We advise that you consider being accompanied by a trusted companion.

2. Consider drinking with experienced women or couples. As an extra precaution, one may wish to ensure there are female healers or facilitators working in their chosen ceremonial setting. Many reputable places now ensure that experienced women are present to assist and safeguard female participants.

3. Check out the location and healer. Check the reputation of any center, shaman, or religious leader you plan to participate in a ceremony with through review sites, past participants, and other experienced people in the area. It is highly advised to consult women. 
4. It is not necessary for healers to touch intimate parts of your body or any area to which you do not consent. Some healings are individually focused on the participant's body, such as sopladas (when the shaman blows tobacco smoke over your body; typically head, chest, spine, hands, and feet) and limpiezas or baños de plantas (plant baths, whereby saturated plants are poured over you) but they do NOT entail touching your private parts. If a shaman, religious leader, or facilitator touches you in a way that makes you feel uncomfortable during the "healing," it is your right to assert that you are not OK with this. You can raise the issue on the spot, with trusted facilitators, organizers of the ceremony, or others outside the ceremonial setting.

5. Curaciones, sopladas, and limpiezas do not require you to remove your clothes. It is certainly not necessary for you to be naked. It is true that in certain Colombian yage traditions, it is usual for participants to be asked to remove their shirt for a limpieza, but it is normal for bras or camisoles to be kept on. This is also true for plant baths, for which you can wear swimwear, underwear, or whatever you feel comfortable with. A healer may offer to do a "special" or individual healing outside of the ceremony that can be very beneficial, but know that you are free to interrupt or decline any treatment. You may wish to ask another participant or a trusted companion to be with you during any such treatment. You have the right to be assertive about your personal needs to feel comfortable, regardless of any resistance from the healer.

6. Look out for warning signs that a healer's intentions with you might be sexual. For example, if he is complimentary of your looks, he is overly "touchy" with you, he tells you his wife does not mind him having sex with other women, he encourages pacts of silence and secrecy between you, he says he wants to teach you love magic, he states that ayahuasca can enhance sexual activity, or he declares that you are special and chosen and offers you ceremonial and religious status. Beware that these kinds of comments and actions have shown that a healer is likely trying to seduce you.

7. Sexual intercourse between healer and patient during ceremonies or directly after the ceremonies is not acceptable in ayahuasca traditions. If a ceremonial leader wants to have sex with you during or soon after the ceremony, he is committing a transgression. This is considered inappropriate and spiritually dangerous in all traditions.

8. Sexual intercourse with a healer does not give you special power and energy. This is a relatively common argument made by men who want to have sex with their ceremonial participants. It can also be a major motivation for why women sometimes flirt, reciprocate flirtations, or willingly engage in sexual relations with healers. While no participant can be told what they can and cannot do with their bodily autonomy, sleeping with a shaman will not make you a shaman, neither will it heal you from your past sexual trauma.
9. Consider cultural differences and local behavioral norms when interacting with native healers. There are some rather benign interactions in Western culture that carry different meanings elsewhere, and can potentially be culturally inappropriate and misunderstood. Overt or internalized misogynistic tendencies that view women as being passive - meaning that men merely need to be verbally or physically suggestive with women for sex to take place - are a widespread problem in South America and elsewhere.

It may be helpful to consider cultural differences when interacting with healers and their community, as certain behaviors, such as being alone with men, being complimentary, prolonged eye contact or "free spirited" behavior, like bathing naked in public spaces, can be misconstrued as gestures of sexual interest. We are not stating that misinterpretation of cross-cultural codes is justified, only that individuals can benefit from being aware of such potential misinterpretations.

10. Consider cultural differences and local clothing customs. Non-local women are often viewed as being desirable, exotic, and sexually promiscuous across cultures. Without condoning these misconceptions and their underlying assumptions, it may be helpful, for your own protection, to consider local clothing customs when attending ceremonies and traveling around in foreign countries. Indeed, the request to not wear revealing clothing is common for many spiritual, meditation, and other healing retreats.

11. Protect your personal space, physically and spiritually, before, during, and after ceremony. Healers with integrity will respect your right to do this. You should not feel obliged to engage in verbal or physical communication with healers, facilitators or anyone else during or following ceremony.

12. Be wary of healers who offer psychoactive substances other than those used during ceremonies. The use of additional psychoactive substances within and outside of ceremonies, besides medicinal plants used in the ayahuasca brew and for shamanic dietas, is sometimes associated with scenarios of abuse. These substances may be presented as "medicines" or therapeutic treatments involving the healing of energy imbalances, or "sexual chakra releases."

13. He's a shaman, not a saint! Remember, shamans and other ceremonial or religious leaders are men (and women) with human flaws, sexual urges, and the potential to abuse their power and cause harm. They do not necessarily live according to the moral standards one might expect of a spiritual leader. Imagining certain individuals to have superhuman qualities is likely an erroneous and dangerous misconception.

14. If a violation occurs, get support. Do not suffer in silence. It is not your fault if you experience abuse. Ideally, speak out on the spot or let someone in a leadership position within the ceremony circle 
itself know. If you are able to report the abuse immediately, it can send a strong message that this will not be tolerated and potentially protect other women from harm. However, you may not feel safe to do this or, you may not fully realize abuse has occurred until after the fact. It is very common for women who have been previously traumatized to experience a "freeze" response during a violation or uncomfortable situation. You have the right to report this abuse afterward, even if you were unable to address it at the time. Seek outside support and, if necessary, legal advice. Different countries have different legislations; try to get informed about your rights and where an incident can be reported.

15. Beware of what might appear to be consensual sex. Consent should happen in a mutually intelligible language where "consent" means the same things to all individuals involved. If you are considering having a sexual encounter with a shaman or facilitator, bear in mind that consensual sex may still involve an imbalance and abuse of power. It is also possible, according to some shamanic practices, for ceremonial leaders to intentionally influence participants into feeling attraction toward them, through love magic and other techniques. Allow time for integration and for the effects of ayahuasca and its often-ensuing sense of empowerment or euphoria to wear off, so that you can apply clear judgment.

16. Beware of getting romantically involved. Feeling attraction toward the ayahuasquero or a fellow participant can happen. As part of their ceremonial experience, some women have dreams and visions about the shaman or other fellow participants, and can get sexually aroused before, during, and after ceremonies. Such feelings are normal and one should not be ashamed of them.

17. If you are aware of or witness sexual abuse, speak up! We are all responsible for combating sexual abuse in our communities. Collaborative efforts are essential to denouncing perpetrators and eradicating sexual abuse in ayahuasca circles.

Resources:

Fernandez, A. C. (2018). Sexual abuse in the contexts of ritual use of ayahuasca. Retrieved from https://chacruna.net/ sexual-abuse-contexts-ritual-use-ayahuasca/. This text is an adaptation of the original: Fernandez, A. C. (2018). Power and legitimacy in the reconfiguration of the yagecero field in Colombia. In B. C. Labate \& C. Cavnar (Eds.), The expanding world ayahuasca diaspora: Appropriation, integration and legislation (pp. 199-216). New York, NY: Routledge. Retrieved from https:/www.researchgate.net/publication/ 326876956_Power_and_legitimacy_in_the_reconfiguration_ of_the_yagecero_field_in_Colombia

Peluso, D. (2018, October 5). Ayahuasca's attractions and distractions: Examining sexual seduction in shaman participant interactions. Retrieved from https://chacruna.net/sexualseduction-ayahuasca-shamanparticipants-interactions/. This text is an adaptation of the original, Peluso, D. (2014). Ayahuasca's attractions and distractions: Examining sexual seduction in shaman-participant interactions. In B. C. Labate \& C. Cavnar (Eds.), Ayahuasca shamanism in the Amazon and beyond. New York, NY: Oxford University Press. Retrieved from https:/www.researchgate.net/publication/290436641_ Ayahuasca\%27s_attractions_and_distractions_examining_ sexual_seduction_in_shaman-participant_interactions (see also https://chacruna.net/community/ayahuasca-communityguide-for-the-awareness-of-sexualabuse/ for additional languages). 